\title{
Smoothing the steep microsurgery learning curve: considering alternative suture sizes for early-stage microsurgery training with in vivo rat models
}

\author{
YuanDian Zheng $^{1}$ (D . John J. Corvi ${ }^{1} \cdot$ Joseph R. Paladino ${ }^{1} \cdot$ Yelena Akelina $^{1}$ \\ Received: 8 January 2021 / Accepted: 4 March 2021 / Published online: 27 July 2021 \\ (c) The Author(s), under exclusive licence to Springer-Verlag GmbH Germany, part of Springer Nature 2021
}

\begin{abstract}
Background Laboratory microsurgery training using invivo rat models is essential for clinical operation. However, challenges existin a structured training course when students transition from a non-livingmodel exercise to a living one. In the present article, we first demonstratethis steep learning curve in early-stage microsurgery training. We then proposethe potential solution of using various sizes of sutures for different trainingpurposes.

Methods Twoseparate preliminary studies were included. First, we reviewed the records of 25 students enrolled in our basic microsurgery training course. Each studentcompleted exercises in a non-living model before graduating to a live animalmodel where their performance on end-to-end arterial and venous anastomoses wasevaluated. Second, we examined the feasibility of different suture sizes in amillimeter microvascular anastomosis. Four groups of identical procedures inrat femoral artery were completed using sutures from 8-0 to 11-0. Patency rateand mean blood flow at $60 \mathrm{~min}$ post-op were measured and compared. Results Thirty-minute patency rates for firstarterial and venous anastomoses were 18/25 and 14/25. Those students who hadnon-patent anastomoses spent significantly longer time than those who hadpatent ones $(p<.05)$. For varioussuture sizes, all groups achieved a $100 \%$ patency rate. No significantdifferences were found between the mean blood flow volume at 60 $\min$ post-op $(p>.05)$.

Conclusions Steep learning curve existed in the early-stagemicrosurgery training when transitioning from non-living to living exercisemodels. The feasibility of using various suture sizes in millimeter anastomosismay be a potential solution for instructors to ease this steep learning curve.

Level of Evidence: Not gradable
\end{abstract}

Keywords Microvascular anastomosis $\cdot$ Microsurgery training $\cdot$ Suture size $\cdot$ Microsurgery learning curve

\section{Introduction}

Laboratory microsurgery training is an essential step before the clinical operation. The basic end-to-end (ETE) arterial anastomosis is among the most fundamental microsurgical procedures and is a focus in microsurgical courses around the globe $[1,2]$. In order to demonstrate clinical readiness, microsurgeons must demonstrate mastery of this procedure

John J. Corvi and Joseph R. Paladino contributed equally to this work.

YuanDian Zheng

Yz3235@tc.columbia.edu

1 Department of Orthopedic Surgery, Columbia University Irving Medical Center, New York, NY, USA in living microvascular anastomosis, such as the use of rat [3-5]. This procedure serves as an important building block to more complex microsurgical procedures [6, 7]. Proper mastery of these skills is critical for future learning and progression [8]. However, the challenge of instruction exists in the early stages of the training process.

We notice one of the major training challenges posed in the early-stage of microsurgery training is the transitioning from non-living exercise modalities such as gloves, plastic tubes, or chicken wings to the living rat model exercises. In the early stage of microsurgery training, the most common curriculum consists of the first eight hours devoted to introducing non-living modalities followed by rat model exercises [6]. However, there are discrepancies between them. First, non-living modalities lack vessel patency feedback and tissue structural similarity to the living rat model. Second, 
there are technical demand differences between practicing on non-living models and a living rat model [9]. These factors may cause a steep learning curve in the early-stage microsurgery training for selective students struggling to transition from non-living to living exercises.

Besides, we believe another potential cause of this steep learning curve is due to the suture size commonly used. Oftentimes, for the millimeter ETE anastomosis exercise, 10-0 Nylon (135-degree taper, 50-microneedle, and 0.02$\mathrm{mm}$ thread) is used $[3,5]$. This may not be most ideal for early-stage living model training in millimeter exercises for those selective struggling students because of its adding difficulty to the already challenged living models. Indeed, a study by Studinger et al. also revealed that only $64 \%$ of surgical residents who had microsurgery training within a year could perform a patent arterial or venous anastomosis in a rat millimeter vascular model using a 10-0 suture [10]. Thus, we propose using the larger suture size to provide more training variability to ease the learning curve. However, no previous research exists comparing various suture sizes to the feasibility in the millimeter vascular exercise to date.

To illustrate the aforementioned issues in microsurgery training, below we present our preliminary findings regarding the steep learning curves in the early-stage microsurgery training and the feasibility of various sutures sizes in millimeter microvascular anastomosis.

\section{Methods}

\section{Overview of anastomosis techniques}

Two separate preliminary studies were included below. All procedures described below were performed in accordance with the guidelines of the Institutional Animal Care and Use Committee (IACUC) at Columbia University Irving Medical Center. The anastomosis techniques used in the following studies were identical.

In short, after the dissection of rat vessels, double clamps with a frame were applied to either artery or vein. Following a transection in the middle of the blood vessel, eight interrupted sutures were placed circumferentially around the anastomosis site in order of two stay stitches at 12 and 6 o'clock following by three additional stitches on each side of the vessel wall anteriorly and posteriorly. Anastomosis time, defined as the duration from first suture placement to the completion of exercises, was recorded. The milking and lift-up tests were performed for patency verification in arterial and venous anastomoses after completing exercise [11].

\section{Illustration of a steep learning curve in the early-stage microsurgery training}

Records of 25 students enrolled in the Columbia University Basic Microsurgery Training course from Sep 2019 to Jan 2020 were retrieved. Each student was instructed to practice non-living exercises, such as gloves and plastic tubes on day 1 of the training. After the careful evaluation of satisfactory proficiency in these non-living exercises, each student proceeded to the first rat femoral arterial and venous $(<1 \mathrm{~mm}$ in diameter) ETE anastomosis. All students used the identical techniques described above to perform the ETE anastomosis. Anastomosis time and 30-min post-exercise patency rate were recorded.

\section{Comparison of the use of sutures from 8-0 to 11-0 in millimeter microvascular anastomosis}

Twenty standardized rats' common carotid artery $(<1 \mathrm{~mm}$ in diameter) ETE anastomosis divided into four groups with suture sizes from $8-0$ to $11-0$ were performed by one author (YZ) (Table 2). Patency was recorded in an identical way as stated above. In addition, arterial blood flow was examined using a transonic doppler flowmeter (Transonic Systems, INC., Ithaca, NY) at 60-min post-operation before euthanizing the animals.

\section{Statistical analysis}

The independent $t$-test was performed to compare the difference between the anastomosis time between those who had patent vessels versus those who had non-patent ones in both

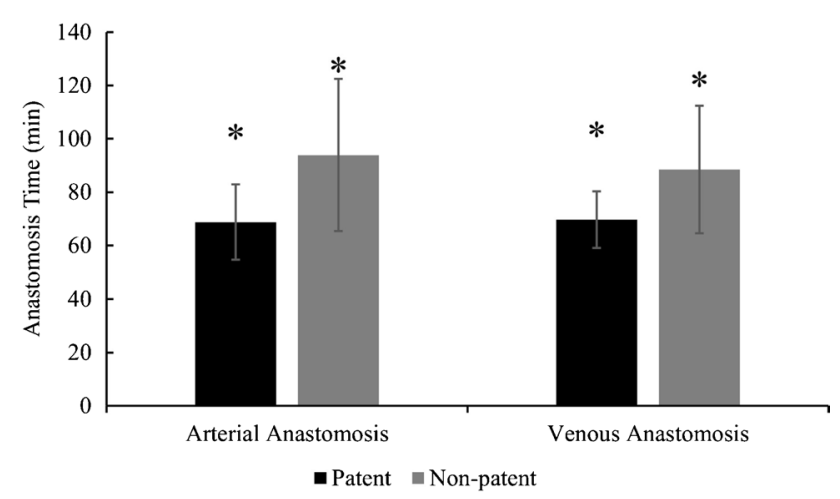

Fig. 1 The comparison of the anastomosis time needed between students who had a patent anastomosis versus those who had a non-patent one in their arterial or venous anastomosis after the satisfactory completion of non-living exercises. Those who had non-patent anastomosis spent significantly longer time than those who had a patent one. *Significance when $p<.05$ 
Table 1 Mean anastomosis time compared to patency rates in past microsurgical students from our basic training program. The negative correlation indicated that the longer the anastomosis, the less the patency rate. Significance is defined as $p<.05$

\begin{tabular}{llll}
\hline$N=25$ & $\begin{array}{l}\text { Mean anastomosis time (min) and stand- } \\
\text { ard deviation }\end{array}$ & $\begin{array}{l}\text { Patency rate at 30-min post- } \\
\text { exercise }\end{array}$ & $\begin{array}{l}\text { Correlation between } \\
\text { time and arterial patency } \\
\text { rate }\end{array}$ \\
\hline Arterial anastomosis & $75.76 \pm 30.71$ & $18 / 25$ & $-.375, p=.033$ \\
Venous anastomosis & $77.92 \pm 28.31$ & $14 / 25$ & $-.337, p=.05$ \\
\hline
\end{tabular}

Table 2 Groups and the perspective postoperative patency rate

\begin{tabular}{|c|c|c|c|c|}
\hline Group $(n=20)$ & $\begin{array}{l}\text { Mean anastomosis } \\
\text { time (min) }\end{array}$ & Patency rate & $\begin{array}{l}\text { Mean blood flow at } 60 \text {-min post- } \\
\text { operation }(\mathrm{ml} / \mathrm{min}) \#\end{array}$ & $\begin{array}{l}\text { Anasto- } \\
\text { motic holes } \\
\text { observed }\end{array}$ \\
\hline $8-0,140$-micron needle, 0.4 metric* & $15.0 \pm .5$ & $5 / 5$ & $1.16 \pm .26$ & $3 / 5$ \\
\hline 9-0, 100-micron needle, 0.3 metric* & $17.5 \pm 2.6$ & $5 / 5$ & $.96 \pm .39$ & $3 / 5$ \\
\hline $10-0,70$-micron needle, 0.2 metric* & $17.0 \pm 1$ & $5 / 5$ & $1.01 \pm .28$ & $0 / 5$ \\
\hline $11-0,50$-micron needle, 0.1 metric $*$ & $26.6 \pm 4$ & $5 / 5$ & $1.4 \pm .30$ & $0 / 5$ \\
\hline
\end{tabular}

*All have 135-degree taper needle, nylon thread, $10 \mathrm{~cm}$ in length, made by Surgical Specialties Corporation; Wyomissing, PA

\#One-way ANOVA shows no significant difference in blood flow volume among groups $[F(3,16)=2.259, p=.121]$

arterial and venous anastomoses. The point-biserial correlation was employed to examine the correlation between total anastomosis time and final patency rate. For the comparison between various suture sizes, one-way ANOVA was performed to evaluate the blood flow rate difference. Significance is defined as $p<0.05$. IBM SPSS v. 26 (Chicago: SPSS Inc.) was used for these operations.

\section{Results}

\section{Students' performance on the first living exercises}

The mean anastomosis time needed for both arterial anastomosis and venous anastomosis was 75.76 $\pm 30.71 \mathrm{~min}$ and $77.92 \pm 28.31 \mathrm{~min}$, respectively. The overall patency rates at 30-min post-exercise were $18 / 25$ and 14/25 for arterial anastomosis and venous anastomosis, respectively. The independent $t$-test showed there was a statistically significant difference with a big mean difference regarding the anastomosis time between those who had patent vessels versus those who had non-patent ones in both arterial and venous anastomoses $(t(23)=-1.94, p=0.033, d=0.9$, and $t(23)=-2.516, p=0.009, d=0.7$, respectively, Fig. 1). Significant medium correlations were found between the increasing anastomosis time and non-patent rate (Table 1). Furthermore, seven out of 25 students had both non-patent arterial and venous anastomoses.

\section{Feasibility of different sutures sizes in millimeter microvascular exercise}

At $60-$ min post-exercise, results show that a $100 \%$ patency rate was achieved, and no statistical difference was found for the blood flow volume regardless of the suture sizes $[F$ $(3,16)=2.259, p=0.121]$ (Table 2 and Fig. 2). Although more bleeding was noticed through anastomotic holes performed by $8-0$ and $9-0$, it was easily stopped after applying gauze and light pressure (Fig. 2).

\section{Discussion}

Our training record points to a jump in difficulty moving to the living model from the non-living model for some selected struggling students who tended to spend much longer time with unsuccessful outcomes. Remedial training on non-living models may be a standard solution for the selective struggling students. However, we caution against this training approach given the following concerns in the practical setting: (1) How can we assess a student's readiness for the transition given students already demonstrated mastery of the non-living model? (2) We cannot hold a student away from his/ her clinical duties by keeping practicing in a laboratory environment on a non-living model. (3) A student cannot finish the designated curriculum offered 
Fig. 2 8-0, 9-0, 10-0, and 11-0 groups at the time of $1 \mathrm{~h}$ after vessel repair. A 8-0 nylon at $1 \mathrm{~h}, \mathbf{B} 9-0$ nylon at $1 \mathrm{~h}, \mathbf{C} 10-0$ nylon at $1 \mathrm{~h}, \mathbf{D}$ 11-0 nylon at $1 \mathrm{~h}$, and $\mathbf{E}$ holes observed for some repairs done by $8-0$ and 9-0 nylon. The bleeding subsided minutes after applying gauze and light pressure to the anastomotic site, which did not affect the final patency. We do not believe this may have any detrimental effects on the skill acquisition process

by a structured program, potentially hurting his/her confidence. (4) It causes animal redundancy because we cannot identify the struggle after working on the animals. However, continuing the living exercise also poses issues in a practical setting as repetitive failure may also harm students' confidence in practicing microsurgery techniques. Indeed, it is not uncommon for us to witness selective students struggling throughout the course of the training.

Here, we recognize a solution needed to bridge a gap between non-living and living training models. We believe the use of larger suture size can provide more training variability to ease the learning curve. Although no evidence or literature existed, we perceive the considerable ease to manipulate a larger sized suture when performing the exercise. In the event a student has progressed beyond non-living training models but still struggling to succeed in in vivo rat models, we propose instructors may consider allowing the use of larger suture sizes to facilitate student progression through a steep microsurgical learning curve, given the feasibility of sutures sizes up to $8-0$ in the present finding. As struggling students begin to demonstrate mastery using larger suture sizes, instructors may consider transitioning a student to finer suture sizes required for the procedure parallel to students' learning progression.

We showed in sole regard to basic rat microvascular exercises, the sizes of suture from 8-0 to traditionally accepted $10-0$ and $11-0$ did not affect a successful anastomosis outcome. This transition from larger to finer suture may be useful for facilitating student progress in demanding microsurgery courses.

While we believe 10-0 suture should remain its common use, we recommend using 9-0 suture for students who have some difficulties in completing their initial animal models training. In some extreme cases, an 8-0 is suitable for use too. After gaining the competency, the student can shift to 11-0 for more advanced training. Table 3 summarizes the authors' proposed recommendations for the choice of suture size in early-stage microsurgery training.
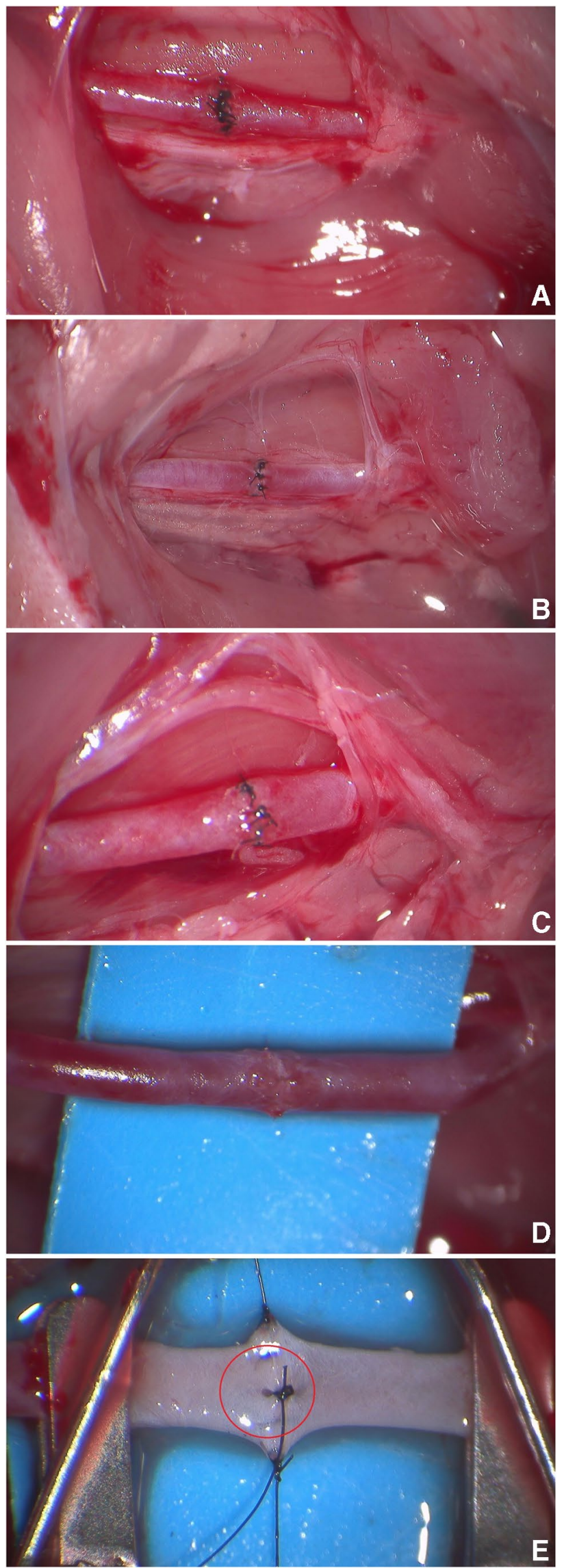
Table 3 Authors' recommendations for the choice of suture size

\begin{tabular}{|c|c|}
\hline Size of the suture & Authors' recommendation \\
\hline $8-0 / 9-0$ & $\begin{array}{l}\text { Students start with either } 8-0 \text { or } 9-0 \text { suture for } \\
\text { non-biological models, such as plastic gloves } \\
\text { or silicone tubes. After gaining competency } \\
\text { under microscope, the student can move from } \\
8-0 \text { to } 9-0 \text {, and eventually } 10-0 \text { to perform } \\
\text { basic anastomosis exercises in non-living } \\
\text { models, such as chicken thighs }\end{array}$ \\
\hline $10-0$ & $\begin{array}{l}\text { Students start with } 10-0 \text { for basic anastomo- } \\
\text { sis exercises in living animal models, such } \\
\text { as rat femoral or carotid vessels. If students } \\
\text { encounter difficulty completing a procedure, } \\
\text { consider switching students to } 9-0 \text { sutures } \\
\text { ( } 8-0 \text { in extreme cases to avoid prolonged } \\
\text { ischemia time and vessel redundancy due to } \\
\text { poor manipulation) }\end{array}$ \\
\hline $11-0$ & $\begin{array}{l}\text { For advanced training (after students demon- } \\
\text { strate competency with } 10-0 \text { sutures), request } \\
\text { students use } 11-0 \text { sutures for basic anastomo- } \\
\text { sis exercises. Emphasis should be focused on } \\
\text { fine motor movements due to needle fragility }\end{array}$ \\
\hline
\end{tabular}

\section{Limitation}

Microsurgery training requires attention to detail in every step to ensure the students can master and finesse their surgical skills. Due to the ongoing COVID-19 pandemic, we could not continue a more thorough investigation to compare the use of various suture sizes in training and their potential impact on microsurgery pedagogy. We suggest a future mixmethod study to prove its efficacy compared to the standard method of training.

Availability of data and material The raw data presented in this study are available from the corresponding author, YZ, upon reasonable request.

Code availability Not applicable.

\section{Declarations}

Ethics approval All procedures presented received approval from the Columbia University Irving Medical Center Institutional Animal Care and Use Committee (IACUC). All use of animals was in agreement with the policies described in the Guide for the Care and Use of Laboratory Animals.
Consent to participate Not applicable.

Consent for publication Not applicable.

Conflict of interest YuanDian Zheng, John J. Corvi, Joseph R. Paladino, and Yelena Akelina declare no competing interests.

\section{References}

1. Stewart CJ, Yusoff SKM, Widdowson D, Lam WL (2016) Microsurgical skill acquisition in a one-day introductory course with performance evaluation using software-assisted scoring system. J Plast Reconstr Aesthet Surg 69:783-788

2. Gomez M, Nicotet C, Verdier J et al (2019) Does the repetition over a short time of a microsurgical suture improve its reliability? Hand Surg Rehabil 38:348-352

3. Shurey S, Akelina Y, Legagneux J, Malzone G, Jiga L, Ghanem AM (2014) The rat model in microsurgery education: classical exercises and new horizons. Arch Plast Surg 41(3):201-208

4. Cooley BC (2009) A laboratory manual for microvascular and microtubal surgery. 2nd ed. Reading: Surgical Specialties Corporation, pp 10-11,39-59

5. Acaland RD, Sabapathy SR (2008) Acaland's practice manual for microvascular surgery, 3rd edn. Louisville: Indian Society for the Surgery of the Hand, $\mathrm{p} 7$

6. Ghanem A, Kearns M, Ballestín A et al (2020) International microsurgery simulation society (IMSS) consensus statement on the minimum standards for a basic microsurgery course, requirements for a microsurgical anastomosis global rating scale and minimum thresholds for training. Injury 51(Suppl 4):S126-S130

7. Macdonald JD (2005) Learning to perform microvascular anastomosis. Skull Base 15(03):229-240

8. Price J, Naik V, Boodhwani M, Brandys T, Hendry P, Lam B-K (2011) A randomized evaluation of simulation training on performance of vascular anastomosis on a high-fidelity in vivo model: the role of deliberate practice. J Thorac Cardiov Sur 142(3):496-503

9. Balasundaram I, Aggarwal R, Darzi LA (2010) Development of a training curriculum for microsurgery. Br J Oral Max Surg 48(8):598-606

10. Studinger RM, Bradford MM, Jackson IT (2005) Microsurgical training: Is it adequate for the operating room? Eur J Plast Surg 28(2):91-93

11. Cooley BC (2009) A laboratory manual for microvascular and microtubal surgery, 2nd edn. Reading: Surgical Specialties Corporation, pp 58-59

Publisher's Note Springer Nature remains neutral with regard to jurisdictional claims in published maps and institutional affiliations. 